\title{
Las falacias Secundum quid y del accidente en Aristóteles. Su interpretación ante-predicativa e ilustración por división ${ }^{1}$
}

\author{
Álvaro Andrés Ledesma Albornoz ${ }^{2}$
}

Recibido: 15 de septiembre de 2015 / Aceptado: 25 de noviembre de 2015

Resumen. A través del reconocimiento del principio de la distinción y su implicación ante-predicativa, las falacias extra-lingüísticas del secundum quid y del accidente propuestas por Aristóteles en los Sophistici Elenchi serán explicadas, probadas, analizadas y resueltas. De esta manera, se postula que las falacias que Aristóteles presenta en dicho libro tienen su raiz en una consideración falaz antepredicativa y no en el paralogismo, lo que abre una nueva forma de analizar las falacias aristotélicas. Con esto, se probará que el análisis de las falacias como paralogismos es posterior, pues se mantendrá la tesis de que la falacia se genera en el nivel de distinción ontológica ante-predicativa y no en el nivel lingüístico del razonamiento. Se propondrá un modelo divisivo que aporta información al modelo inclusivo de la lógica tradicional, esto porque él nos permite dar cuenta del principio de la distinción.

Palabras clave: Aristóteles; "Refutaciones sofísticas"; falacias; accidente; Secundum quid; principio de la distinción.

\section{[en] Aristotle's Secundum quid and accident fallacies. Their fore-predicative interpretation and illustration by division}

\begin{abstract}
Through the recognition of the principle of distinction and its fore-predicative implications the extra-linguistic fallacies of secundum quid and accident, proposed by Aristotle in the Sophistici Elenchi, will be explained, proved, analyzed and solved. Thus, it is postulated that the fallacies presented by Aristotle in this book are rooted in a false fore-predicative consideration and not in the paralogism. This consideration will open a new way of analyzing Aristotle's fallacies. With this, we will prove that the analysis of the fallacies as paralogisms is posterior, for we will stand by the thesis that states that the fallacy is generated in the ontological fore-predicative distinction level and not at the linguistic level of reasoning. A divisive model that provides information to the inclusive model of traditional logic is proposed in the way that it allows us to take account of the principle of distinction.
\end{abstract}

Keywords: Aristotle; "On Sophistical Refutations"; fallacies; accident; Secundum quid; Distinction principle.

Sumario. 1. Introducción; 2. ¿Por qué la división es anterior a la predicación?; 3. Análisis de las $S E$ según el nivel ante-predicativo; 4. La predicación afirmativa entendida como división; 5. Esquema argumentativo y su respectivo esquema divisivo; 6. Tipos de división según Boecio; 7. Mostración del esquema divisivo en el tratamiento de las falacias; 8 . Diferencia entre las falacias del accidente y del secundum quid; 9. Conclusión; 10. Referencias bibliográficas.

Cómo citar: Ledesma Albornoz, A.A. (2017): "Las falacias Secundum quid y del accidente en Aristóteles. Su interpretación ante-predicativa e ilustración por división", en Revista Anales del Seminario de Historia de la Filosofía 34 (1), 11-33.

\footnotetext{
Esta investigación fue posible gracias al financiamiento de CONICYT Chile.

Instituto de Filosofía. Pontificia Universidad Católica de Chile

aaledesma@uc.cl.
} 


\section{Introducción}

Hablar del método de la división en Aristóteles no parece absurdo ${ }^{3}$, aun después de la crítica que el filósofo hace de él en los Analíticos Posteriores II 5, $91 b 33$ y ss., en donde se dice que el método de la división sirve sólo para "indicar", mas no para demostrar'. Sin embargo, la división puede dar noción de "qué es" la cosa y por ello Aristóteles la acepta como método para definir 5 :

Para establecer una definición mediante las divisiones es preciso apuntar a tres $<$ objetivos $>$ : tomar los predicados en el qué es, ordenarlos $<$ señalando $>$ cuál es primero o segundo, y que éstos sean todos (A. Po. II, 13, 97a23-27).

Como se puede ver, para que la definición sea correcta, es preciso cumplir con la exhaustividad:

[...] ¿qué impide añadir, o quitar algo de la entidad, o rebasarla en algún aspecto? Éstas son, pues, argumentaciones que pueden fallar, pero que cabe solventar tomando todo lo que hay en el qué es y haciendo la división de manera continua tras haber postulado el primer < término > y no descuidando ninguno (A. Po. II, 5, 91b25-31).

Es precisamente esta exhaustividad la que no encontramos en los sofismas expuestos en los Sophistici Elenchi (SE), y hay razón para ello, pues Aristóteles dice que los sofistas no razonan correctamente, sino que sólo aparentan hacerlo $(S E, 1$, 164a y ss.). La actividad del sofista es, en consecuencia, contraria a la del filósofo y científico, ya que mientras los últimos buscan la exhaustividad en la definición, el sofista busca la superficialidad y la ambigüedad para disponer de elementos que le permitan aparentar una refutación, falsear, conducir a la paradoja, llevar a la incorrección, o hacer que su oponente hable incorrectamente $(S E, 3,165 \mathrm{~b} 12$ 23). De lo cual podemos entender que Aristóteles considera que los sofistas no realizan razonamientos válidos $\left(\right.$ silogísticos) ${ }^{6}$. Lo que probaremos en el presente

3 Es reconocido por los especialistas que la lógica aristotélica está claramente influenciada por la definición platónica. Kneale lo confirma: “A despecho de su repudio de la teoría platónica de las Formas, la caracterización aristotélica de la definición -y el pensamiento lógico de Aristóteles en general- se mueve indudablemente en la esfera de influencia de semejante tradición. Su formación platónica le llevaba a buscar el objeto último de intelección y el fundamento de la inferencia válida en un sistema o encadenamiento de Formas cuyas mutuas interrelaciones limitarían las posibilidades de la existencia real, determinando así la corrección o incorrección del pensamiento científico" (Kneale, 1980, p. 20). Si se logra probar en este estudio que la división platónica está presente en el tratamiento de los Sophistici Elenchi, esto favorecería a la tesis de 1929 de F. Solmsen, quien ubicó los Tópicos, y con ellos los Sophistici Elenchi, al principio de la producción lógica de Aristóteles, pues esto mostraría una influencia platónica más marcada en dicho libro.

4 La división es concebida por Platón y Aristóteles como un mecanismo de definición que busca el "qué es" a través del proceso de concatenar varios términos según parezca correcto. Sin embargo, Aristóteles dirá que no podemos estar seguros de cuáles términos son esenciales a la definición y cuáles de ellos no lo son, pues en la división surgen términos accidentales que no delimitan el "qué es". El hecho de que la división sea ejecutada dividiendo un género en sus especies no garantiza una definición válida. Por lo tanto, Aristóteles dirá que la división puede no ser confiable como si fuere un razonamiento.

Cf. A. Po. II, 10, 94a11-13.

6 Razonar correctamente sobre las cosas es propio de la ciencia. Por otro lado, el razonamiento sobre el lenguaje (y la propia manera de razonar) es materia de la dialéctica. En cuanto a la sofística, Aristóteles nos dice que ésta razona sobre lo mismo que la dialéctica pero de una manera asimétrica: se admite la ambigüedad (y homonimia) del término medio, la conclusión no es necesaria, se aplica conversión a proposiciones tipo A sin respetar las 
estudio es que los 'razonamientos' sofísticos son falaces, no sólo porque concluyan incorrectamente, sino porque sus premisas llevan impresas, desde un principio, falacias que se han producido en la consideración ante-predicativa del objeto del cual se habla. Y es precisamente en la definición (al modo de la división) en donde se insertan estas incorrecciones.

Ahora, si probamos que toda predicación lleva implícita una división y, por el hecho de que toda proposición lleva predicados y todo silogismo proposiciones, podríamos decir que las falacias expuestas por Aristóteles en las $S E$ se originan, no en el silogismo como tal, sino en la mala comprensión de los términos que componen sus proposiciones. Esto supone que la consideración falaz se produce en confrontación con las cosas mismas llevando este error al predicado, produciendo así la falacia que después será asumida en la argumentación ${ }^{7}$. Si bien el tratamiento del nivel predicativo (donde se imbrica la falacia) y argumentativo (donde devine el paralogismo) han sido aceptados y tratados por los comentaristas desde la antigüedad, el nivel de la división no ha sido hasta ahora reconocido. El objetivo de este trabajo es investigar este nivel anterior al que llamamos consideración falaz (el cual reconocemos haciendo uso del método de la división), y afirmarlo como el fundamento de las falacias que presenta Aristóteles en $S E^{8}$.

reglas de la conversión (a saber, que al convertir una proposición tipo A se debe subalternar: Todo S es P: Algún $\mathrm{P}$ es S). Esto último se da en la falacia del $A c$, etc.

Si bien Aristóteles concede que el razonamiento erístico, aquel de la sofística, razona aparentemente desde

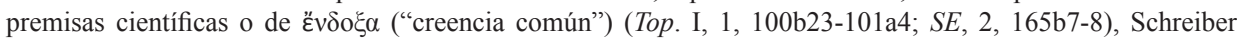
advierte correctamente que Aristóteles regularmente describe sus premisas como endóxicas (o aparentemente endóxicas), estando así "comprometido con la noción de la erística como parásito del razonamiento dialéctico más que del científico.” (Cf. Schreiber, 2003, Intr. nota8). Como se advertirá en este trabajo, esta interpretación es correcta, pues la falacia se produce por la consideración errónea (que pasa de vista la distinción entre predicados esenciales y accidentales), la cual es llevada a predicación. Esta consideración defectuosa de la división no alcanza el nivel científico del "qué es", pues es usada por los sofistas en cuanto acepta la superficialidad y la apariencia.

7 Se puede objetar diciendo que Aristóteles considera que el error se produce en el juicio. En efecto, Aristóteles escribe: "La percepción de los sensibles propios es siempre verdadera y se da en todos los animales, mientras

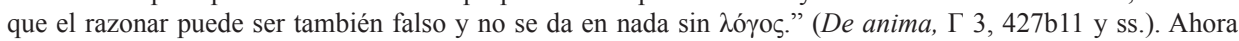

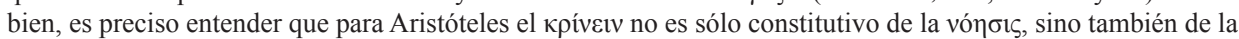

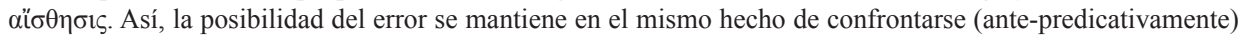
con la cosa, pues todo confrontarse es un considerar desde algún respecto al ente. La composición [ $\sigma 0 ́ v \theta \varepsilon \sigma i \varsigma]$ y

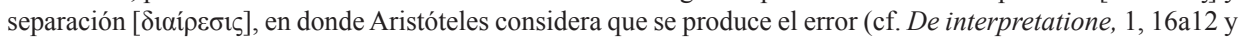
ss.), representan un paso posterior a la consideración falaz, pues el $\lambda$ ó $\gamma \circ \varsigma \psi \varepsilon v \delta \eta ́ \varsigma$ depende primero de una falsa consideración.

8 Aristóteles divide las falacias en aquellas en función del lenguaje ( $\varepsilon \xi \omega \tau \tilde{n} \varsigma \lambda \varepsilon \varepsilon \xi \varepsilon \omega \varsigma$ ) y en aquellas al margen del

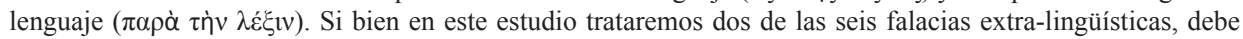
entenderse desde un principio que nuestra hipótesis tiene la intención de extenderse a las 12 falacias (así como a la ignoratio elenchi que Aristóteles presenta como aquella que engloba todas las anteriores (SE, 4 y 5)). Ello porque los objetos materiales, así como los objetos lingüísticos: 'nombres'y predicaciones simples y compuestas (en el caso de la falacia de la pregunta compuesta) pueden tomarse como 'objetos de la consideración' y por tanto ser considerados falazmente.

Un ejemplo de cómo la consideración falaz opera en los objetos lingüísticos es claro en la falacia de la homonimia. Por ejemplo, la palabra perro puede ser considerada falazmente si se supone que ella refiere a un sólo 'objeto material' (o bien a una región del ente). Si esto sucede, siempre que se use se limitará su referencia a 'una cosa', a saber, al canino. Pero bien existen otros significados de esta palabra, por ejemplo, también puede referir a un animal marino. La falacia de la homonimia se encuentra originalmente, no en la conclusión que toma erróneamente el término medio como 'lo mismo' cuando éste refiere a dos cosas diferentes, sino que se encuentra originalmente en la consideración falaz del nombre en su restricción. Ahora bien, si es posible reducir las falacias lingüísticas a la homonimia y ambigüedad de la forma que se expone en SE, 4, 166a15-19 y se prueba que la homonimia se divide según la tercera rama del tipo secundum se (de una palabra en sus 


\begin{tabular}{|l|l|l|}
\cline { 2 - 3 } \multicolumn{1}{c|}{} & \multicolumn{1}{c|}{ Actividad } & \multicolumn{1}{c|}{ Resultado } \\
\hline Nivel ontológico & $\begin{array}{l}\text { Concepción ante-predicativa } \\
\text { (ilustrada por la división) }\end{array}$ & Error (consideración falaz) \\
\hline \multirow{2}{*}{ Nivel lingüístico } & Predicación & Falacia \\
\cline { 2 - 3 } & Argumentación & Paralogismo \\
\hline
\end{tabular}

Esta tesis queda clara considerando que para Aristóteles no toda falacia es un paralogismo9, pues la falacia se produce en un momento anterior: En Categorías 4, Aristóteles dice que el nombre por sí sólo no puede ser ni verdadero ni falso. Para que se dé veracidad o falsedad debe hacerse una afirmación o una negación. Para que se dé afirmación debe predicarse algo del nombre, y es en esta combinación donde se produce la falacia ${ }^{10}$. Ahora bien, si es claro que toda predicación es una combinación entre sujeto y predicado ${ }^{11}$, en este trabajo se demostrará también que antes de esta

significaciones) o bien, si es una oración en la segunda rama de mismo tipo (de un todo en sus partes) (cf. sección 5 de este estudio), entonces podremos proponer la hipótesis de que tanto las falacias lingüísticas como las extralingüísticas surgen por la consideración falaz antepredicativa.

Esta misma hipótesis es insinuada por Schreiber cuando resalta que "cada ejemplo de razonamiento falaz resulta persuasivo tan sólo si la víctima mantiene una particular presuposición falsa del lenguaje o del mundo (Schreiber, 2003, p.4. Trad. propia). Sobre el pasaje de SE 166a15-19 remito a Schreiber, 2003, Appendix 3, p.179.

9 Analizando los diferentes sofismas podemos dar cuenta que algunos tienen la forma del silogismo, pero que otros no pueden reducirse a dicha forma, hecho que en la antigüedad obligó a los comentaristas de Aristóteles a modificar los sofismas para hacerlos coincidir con el método silogístico: Los escoliastas bizantinos interpretaron la falacia del $A c$ no por su descripción en las $S E$, sino según dos pasajes de Categorías (3,1b10-11; 5, 2a2934) en donde se habla de una falacia del mismo nombre, pero que no mienta exactamente lo mismo. Esta interpretación después pasa a Buridan, quien define la falacia del $A c$ como un defecto del silogismo el cual se produce cuando la conclusión no sigue la necesidad de las premisas (cf. Buridan, Compendium Totius Logicae). Cf. Bueno,1988, p.20-21.

Habría que agregar que Boecio da un indicio de la razón por la cual no deberíamos considerar el tipo de argumentos que se ofrecen como ejemplos en las $S E$ como silogismos. Boecio dice que el silogismo se define como "una oración en la cual a partir de ciertas cosas establecidas y aceptadas, alguna otra cosa que aquellas que fueron establecidas y aceptadas, se sigue por necesidad, a causa de las mismas que fueron aceptadas." No podemos considerar silogismos proposiciones como "Ves; por lo tanto, vives, o Eres hombre; por lo tanto, eres animal" (los estoicos consideraban erróneamente esos ejemplos como silogismos). "Pues -continua Boecioel silogismo es un conjunto de algunas <proposiciones $>$. Pero ciertamente un conjunto no puede ser sino de muchas cosas, y quienquiera que hubiese establecido una sola proposición, no llegaría a concluir, y por tanto no haría ningún silogismo. El silogismo, para ser muy conciso, debe ser probado a partir de dos proposiciones." (Boecio, De syllogismo categorico, 821A7, p.69,8).

Existe gran aceptación a pensar que los Tópicos, junto con los Sophistici Elenchi, fueron escritos antes de que Aristóteles desarrolle su sistema de la lógica silogística. Además podemos observar que estos tratados tienen un tratamiento informal, pues no hay uso de variables lógicas o análisis silogístico (Cf. Bueno, 1988, p.8).

10 Se puede objetar que la tesis de este estudio entra en conflicto con la afirmación que hace Aristóteles en $S E 4$, $166 \mathrm{~b} 10$, donde dice que la falacia se produce por tomar lo no idéntico como si fuera idéntico. Se objetaría que ello sería anterior a la predicación de la división. En este caso se concedería lo dicho, mas cabría aclarar que ello es precisamente lo que aquí se muestra. Quien objeta habrá pasado de vista que la división es un modelo articulado (predicativo) cuya intención es ilustrar la forma en la que la consideración falaz (ante-predicativa) ha operado. No se postula aquí que la consideración falaz es consecuencia de una mala deliberación predicativa (al modo de la división); al contrario, se postula que la consideración falaz lleva el error a la predicación. Por tanto, si se entiende el tomar lo no idéntico como idéntico en tanto que considerar al ente bajo un respecto que no le es propio, como si lo fuera (y así confundir predicados esenciales con accidentales), entonces la tesis que Aristóteles presenta en $S E 4,166610$ está en perfecta consonancia con lo aquí propuesto.

11 Desde Aristóteles la predicación ha sido entendida como la combinación de un sujeto y un predicado. Este estudio presentará la posibilidad de estudiar el fenómeno de la distinción según la articulación de lo distinguido en la división, donde el sujeto divide el predicado afirmando, con ello, precisamente aquello de lo que se ha distinguido. 
combinación (que se da en un ámbito lingüístico) se encuentra una consideración errónea de la cosa (en un ámbito ontológico), y que ésta puede ser ilustrada al modo de la división. A la consideración ante-predicativa la llamamos distinción.

En De Interpretatione, 11, Aristóteles dice que si no distinguimos los predicados esenciales de aquellos accidentales podemos caer entonces en error al momento de formar una unidad en cuanto a los términos. Así, cuando los términos son esenciales puede formarse una unidad entre ellos, por ejemplo, decir de hombre que es animal y bípedo, es lo mismo que decir que es un animal bípedo. Pero cuando lo predicado es accidental al sujeto el error se produce en la formación de la unidad, por ejemplo si decimos que el hombre es zapatero y bueno y concluimos que por tanto es un buen zapatero. De la misma manera, si digo que Homero es un poeta, no puedo concluir de él que es simplemente (éste es un caso de la falacia del Secundum quid ${ }^{12}$ ), porque el "es" se predica de él accidentalmente. De esta manera, si no se reconoce la diferencia entre predicados esenciales y accidentales no se está reconociendo tampoco la consideración ante-predicativa de la división, pues en cuanto a hombre, éste pertenece a los animales bípedos, pero, en el caso del zapatero, "ser bueno" se predica del hombre y no de su accidente (y si se transfiere el predicado al accidente se comete la falacia del accidente ${ }^{13}$ ): se rompe así la división, ya que "bueno" no pertenece a la definición de "hombre zapatero", sino que es un predicado accidental que sobreviene al hombre, pero no a su actividad.
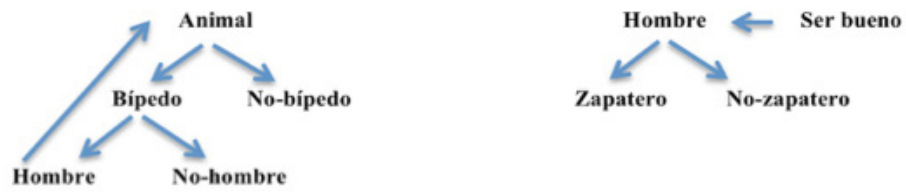

Por ello, los sofistas cometen error ante-predicativamente, ya que su error no está en el predicado, sino que el predicado lleva de ya su error, pues los sofistas no distinguen entre predicados esenciales y accidentales y por ello no distinguen que en las cosas mismas algunos atributos se dan esencialmente y otros accidentalmente. Aunque Aristóteles se concentre en la predicación, la división es una constante implícita en el tratado de las $S E$ y por tanto en la teoría de las falacias. En el presente estudio presentaremos cómo se aplica esta visión a las falacias del $A c$ y del $S Q$ que se exponen en los Sophistici Elenchi, ya que son ellas las que retoma Aristóteles en De Interpretatione, 11, y son las que ilustran en mayor medida la consideración falaz.

\section{2. ¿Por qué la división es anterior a la predicación?}

El hombre, al enfrentarse al mundo, debe distinguir. Al distinguir clasifica, y clasifica según cómo son las cosas. Por ejemplo, observa que hay animales, pero que éstos difieren entre sí, pues unos son mamíferos, otros reptiles, otros aves y otros anfibios. De la misma manera, entre los mamíferos tiene aquellos que son racionales y aquellos no-racionales, y así consecutivamente. Una vez que ha dividido es capaz de predicar: el hombre es un animal, mamífero y racional. Aristóteles dice que la

\footnotetext{
Desde ahora siempre referida como $S Q$.

13 Desde ahora siempre referida como $A c$.
} 
división nos concede el "qué es" de las cosas y, para poder afirmar o negar algo, es preciso primero saber el "qué es" para garantizar que nuestra predicación sea correcta y no errónea. Pero Aristóteles nos dice también que "[e]l que define y divide no tiene por qué conocer para nada todas las cosas que existen" ( . Po. II, 13, 97a2327), lo cual prueba que la división se remite a la experiencia de las cosas mismas, ya que en la experiencia es imposible conocer todos los términos. Es evidente que por ello la división admite el error.

Tomemos un ejemplo de las $S E$ para mostrar lo dicho hasta aquí:

$\mathrm{Y}$, si el triángulo tiene sus ángulos equivalentes a dos rectos, $\mathrm{y}$ se da accidentalmente ${ }^{14}$ en él ser una figura, o una cosa primordial, o un principio, no será aquello [es decir, equivalente a dos rectos] por ser figura, cosa primordial o principio: pues la demostración no es en cuanto figura ni en cuanto cosa primordial, sino en cuanto triángulo $(S E, 6$, 168b1-5).

No se dice de toda figura que sea triángulo, pero sí de todo triángulo que sea figura, por lo tanto, el predicado "figura" abarca al sujeto "triángulo".

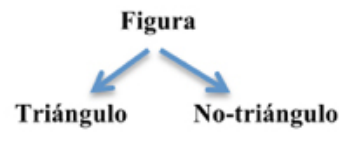

De ello, si considero falazmente aquello y predico a "Figura" un predicado que se dice de "Triángulo" pero que no se dice de otra figura, entonces cometeré la falacia del $A c$. En este caso, si predico que en todo triángulo la suma de sus ángulos equivale a dos rectos y, a más de ello, no cometo una consideración falaz (pensando que el sujeto excede al predicado, esto es, que el triángulo abarca a la "figura"), entonces no tendré falacia. Pero si considero falazmente que "triángulo" se predica de "figura", y cuando digo que un cuadrado (que se encuentra entre los No-triángulos) es una figura (lo cual es correcto), entonces debo concluir que al sumar todos los ángulos del cuadrado obtendré dos rectos, lo cual es un error. Así se muestra que la consideración ante-predicativa opera según la distinción (ilustrada por la división) y que sólo después de que ésta haya sido ejecutada es posible "combinar" sujetopredicado y afirmar o negar algo.

La confrontación ante-predicativa con las cosas, según la cual las tomamos 'en cuanto que esto o lo otro', ha sido conceptualizado como distinción. Al principio que opera predicativamente (y que da evidencia del fenómeno ante-predicativo), según la división presente en toda proposición afirmativa, lo llamamos principio de la distinción, y dice: En toda proposición afirmativa hay una composición de sujeto $(S)$ y predicado $(P)$, pero al mismo tiempo hay una división: el sujeto divide el predicado en todo lo que el sujeto abarca de él $(P-S)$ y en todo lo que es el predicado por fuera de aquel sujeto $(P-n o-S)$.

\section{Análisis de las $S E$ según el nivel ante-predicativo}

En general, Aristóteles en las $S E$ nos provee una suerte de descripción de cada falacia a la que sigue una descripción de los términos que la componen y una ejemplificación.

14 En este caso, Aristóteles habla de "accidente" como equivalente a "consecuencia". 
En esto último cabe recalcar que no siempre se ofrece un paralogismo y, de hecho, en ciertas falacias éste parece ser excluido (como lo es en el caso de la falacia de la acentuación ${ }^{15}$ ). Asimismo, los ejemplos que se dan no son siempre consistentes con la falacia relacionada. Analicemos el siguiente ejemplo que Aristóteles relaciona con la falacia del $A c$ para argumentar: 1. Que el error es anterior al paralogismo. 2. Que este ejemplo pertenece a la falacia del $S Q$ y no a la del $A c$.

Si Córisco es distinto de un hombre, es distinto de sí mismo: pues es hombre. O, si es distinto de Sócrates, y Sócrates es hombre, dicen que queda así convenido que es distinto de un hombre por coincidir que, aquel del que se dijo que era distinto, es un hombre ( $S E$, $5,166 \mathrm{~b} 35)$.

Aristóteles nos presenta un argumento que podríamos disponer al modo de dos silogismos:

Córisco es distinto a Sócrates.

Sócrates es hombre.

Luego, Córisco es distinto de un "hombre".

Si Córisco es distinto de un "hombre"

Y él es un hombre

Es pues, distinto de sí mismo.

Si bien podemos arreglar el argumento en un silogismo, hay que convenir en que la falacia se ha producido, no por concluir erróneamente, sino por considerar mal lo predicado. Como bien se dice en $S E$, 4, 166b10, la clave del sofisma es interpretar lo 'no idéntico' como 'idéntico'" ${ }^{16}$. En el ejemplo, el error radica en considerar falazmente el término "hombre". En la conclusión del primer silogismo se dice que Córisco es distinto de un "hombre", ese hombre es Sócrates, y por lo tanto el término "hombre" está restringido a él. Sin embargo, se toma, en el segundo silogismo, el mismo término "hombre" sin restricción. Al irrespetarse la restricción este ejemplo es un ejemplo de la falacia del $S Q$. La consideración falaz está dada, no en el transferir un atributo de la cosa a su accidente (o viceversa), sino que se encuentra en pasar de vista la restricción. Nótese que cuando se hace la segunda predicación "Sócrates es un hombre", se predica de Sócrates algo esencial, a saber, que es hombre. Pero la falacia está en que este predicado, aunque es esencial, no equivale a la cosa misma. Así, cuando digo "Sócrates", digo "un hombre", pero el sofista lo entiende como decir que Sócrates es " $E l$ Hombre" (el universal), equivaliendo ambos términos. Sócrates se toma como si fuera una división perfecta de Hombre (el sujeto iguala al predicado). Por ello, cuando digo que Córisco no es Sócrates, el sofista asume que he dicho que Córisco no es hombre ${ }^{17}$. Lo interesante de esta nueva consideración

15 "En función de la acentuación no hay argumentos, ni escritos ni hablados, excepto que surjan unos pocos [...]" $(S E, 21,178$ a). Aristóteles confirma aquí que hay la posibilidad de formar paralogismos a través de las falacias, pero que ellas son anteriores a éstos, pues en la falacia de la acentuación queda claro que en 'lo dicho' (como objeto lingüístico) ya está dada la falacia.

16 El texto aquí refiere a que la confusión está en no respetar las divisiones de las diez categorías o predicamentos que se han mostrado en Cat. 4 y Top. I, 9.

$17 \mathrm{~S} \Leftrightarrow \mathrm{H} ; \mathrm{C}=>\Gamma \mathrm{S} ;$ Luego $\mathrm{C}=>\Gamma \mathrm{H}$. El error está en la primera consideración, tomar a $\mathrm{S} \Leftrightarrow \mathrm{H}$. 
es que hecha luz sobre nuestra interpretación de las falacias como un campo en donde podemos observar la mala consideración ante-predicativa a la manera de la división. Pues igualar dos términos es equivalerlos a la manera de la definición. Y según Aristóteles la división es el método de la definición. Por ello es sensato pensar que en una definición defectuosa opera una división mal considerada ${ }^{18}$.

Es claro que no hay argumentación (falaz) (silogismo/paralogismo) si antes no hay una (falsa) predicación y no hay ésta última si antes no hay una división (mal) considerada. El punto no es negar que se puedan construir paralogismos de las falacias, sino reconocer que en ellos mismos está implícita una predicación que lleva en ella ya una consideración errónea de las cosas.

Schreiber (2003) percibe con fortuna que Aristóteles ha mentado dos fenómenos en su tratamiento de las falacias. El primer fenómeno es el de un nombre con varios significados (fenómeno lingüístico), y el segundo es el de un objeto en varios nombres (fenómeno no-lingüístico). Schreiber escribe:

Aristóteles concibe el factor de que las palabras tengan varios significados como un fenómeno lingüístico, pero concibe el hecho de que las cosas tengan múltiples significados un fenómeno acerca de las cosas (Schreiber, 2003, p.102. Trad. propia).

Ahora lo más interesante que encontramos en el aporte de Schreiber es que a línea seguida acudirá a la división para explicar estos fenómenos dicotómicos. Schreiber nos ofrece el siguiente cuadro:
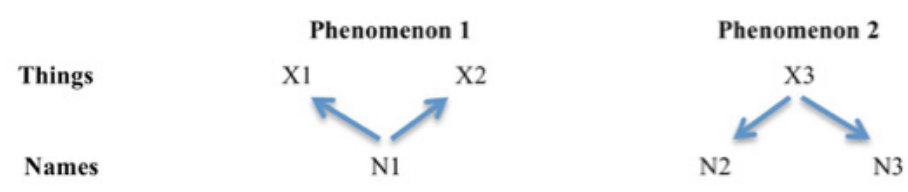

Donde X1, X2 y X3 son objetos extralingüísticos y N1, N2 y N3 son nombres.

La columna uno ilustra la posibilidad de que un mismo nombre refiera a diferentes objetos. La columna dos mienta la posibilidad de que un objeto refiera a varios nombres. Schreiber después dirá que aunque concuerda con Aristóteles en que estos fenómenos son diferentes, considera que ambos son características del lenguaje y no de las $\operatorname{cosas}^{19}$. Aunque estamos de acuerdo con Schreiber en pensar que el hecho de que una cosa tenga dos nombres (véase X3) no la distingue ontológicamente de aquella que tenga tan sólo uno (X2 o X1), no pensamos que la falacia se origina explícitamente en el lenguaje, sino en la consideración ante-predicativa de la cosa. De aquí que el uso de la división en el análisis de Schreiber está limitado al lenguaje, mientras que en el análisis que se desarrollará en este estudio expandimos la concepción divisiva al ámbito anterior al mismo. Ahora bien, con la alusión que

18 Aparte del análisis ontológico queda claro que una visión lingüística de los ejemplos aristotélicos de la falacia del $A c$ es posible. Claramente Aristóteles no estimaba correcta esta consideración (SE, 24, 179b38-180a7), ya que, como resalta Schreiber, ésta no es aplicable a la totalidad de los ejemplos dados, sobre todo al del triángulo. Ahora bien, si bien varios se pueden explicar bajo el punto de vista lingüístico, el principio de parsimonia nos indica que su origen primero se produce en la distinción falaz entre predicados accidentales y esenciales (cf. Schreiber, 2003, p.117-127). Aquí tan sólo queda en evidencia que el modelo de la división se aplica a la consideración lingüística como a la ontológica.

19 Cf. Schreiber, 2003, p.102. 
hace Schreiber a la división (aunque después no trabaja netamente con ella) queda implícito el que tanto las falacias lingüísticas como las extra-lingüísticas están posibilitadas a ser entendidas bajo el modelo divisivo.

\section{La predicación afirmativa entendida como división}

En toda predicación afirmativa hay implícita una distribución (una pertenencia), un "no dejar intacto" el predicado; por tanto, en toda predicación afirmativa hay una división. Conforme a la lógica antigua, el predicado es siempre más extenso que el sujeto, por tanto, de alguna manera el sujeto participa del predicado. Se hace patente en ello que para toda inclusión existe una división ${ }^{20}$. Esto es lo que designa el principio de la distinción.

1. Singular: Sócrates es un ser humano.

Modelo inclusivo

Modelo divisivo ${ }^{21}$
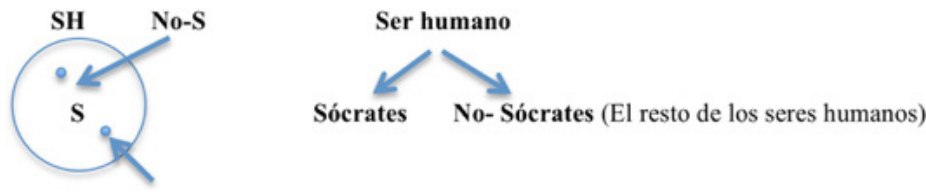

2. Particular: Algunos cristales son transparentes ${ }^{22}$.

C
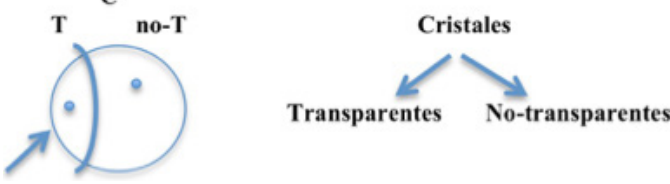

3. Universal: Todo hombre es animal
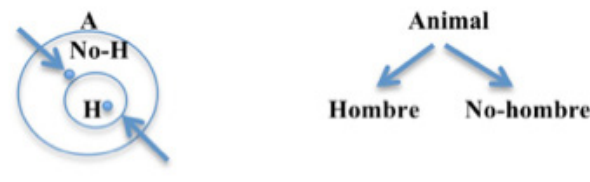

20 Ver nota 23.

21 El modelo divisivo complementa al modelo clásico de la inclusión. Si bien en toda predicación se incluye al sujeto en su predicado, también en toda predicación (afirmativa) se excluye a todo lo que no es el sujeto de ese predicado. Esto es, cuando se dice 'Sócrates es un hombre', se dice que el sujeto 'Sócrates' está incluido en su predicado 'hombre', pero al mismo tiempo se dice que existe un predicado "hombre" que se divide en Sócrates y en todo lo que no es Sócrates pero que participa del predicado, esto es, el resto de los seres humanos. La división lleva a predicación lo que se ha distinguido en confrontación con las cosas. Siempre que se divide se distingue y siempre que se distingue se produce una división. La división es la articulación de lo ante-predicativamente distinguido. Ahora bien, es prudente señalar que en el caso de que se dé una definición perfecta, donde el sujeto iguale al predicado y se produzca una tautología: los términos no se distinguen. En este caso es absurdo dividir, pues no se ha distinguido nada, se ha dicho perfectamente "lo que es" (claro que esto se distingue de algo otro que ciertamente no está siendo predicado; pero es claro que no se distinguen los términos enunciados). Por ejemplo, si se dice: 'el ser es', se dice una tautología, no se ha distinguido nada aunque el enunciado aparenta hacerlo. En estos casos, donde el sujeto iguala al predicado, la división es imposible.

22 En este caso la división es secundum accidens: un sujeto se divide en sus accidentes. No debe confundirse pensando que aquí "transparente" es más extenso que "cristales", porque al añadir "algunos" estoy involucrando una división de un sujeto y no de un predicado. 
En los esquemas se puede advertir que siempre que existe un modelo inclusivo para representar una predicación afirmativa existe un modelo divisivo que representa esa misma predicación (y él siempre refiere directamente al objeto que está siendo distinguido). Siempre que exista una inclusión existe una división.

Conviene aclarar, entonces, que en esta relación entre inclusión y división estamos suponiendo las siguientes reglas para la correcta formación de una proposición:

1. El predicado debe ser más extenso que el sujeto ${ }^{23}$.

2. El predicado está dividido por el sujeto.

a. Esto se expresa por el Axioma 2 de la teoría silogística ${ }^{24}$.

3. Toda proposición afirmativa opera por el principio de distinción $n^{25}$.

\section{Esquema argumentativo y su respectivo esquema divisivo}

Así como existe un esquema divisivo para todo esquema inclusivo en el ámbito de la predicación, también existe un esquema divisivo para el esquema argumentativo.

\section{Silogismo Científico:}
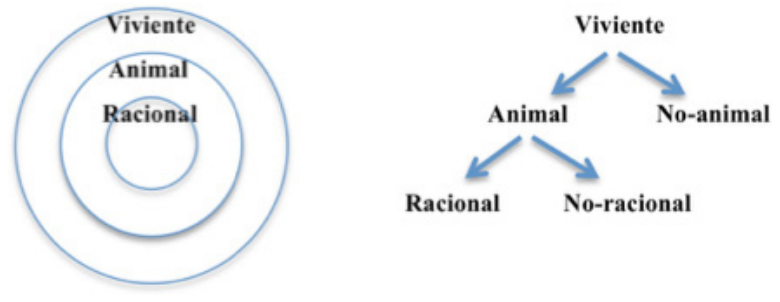

23 Boecio, cuando nos habla del orden de la enunciación, bien dice que "siempre lo que es predicado excede y sobrepasa al sujeto o lo iguala. En efecto, nunca se halla un predicado menor que el sujeto." (Boecio, Sobre el Silogismo Categórico, 798B1/p.16,16). Esta consideración es válida para toda la lógica anterior a la lógica matemática en la cual los términos son vaciados de contenido (ya no refieren a las cosas) y, por tanto, pueden ser dispuestos en cualquier orden sin alterar el producto. En el caso de las proposiciones co-extensivas, esto es, aquellas en donde el sujeto iguala al predicado, claramente el principio de la división no se aplica. Esto no es una refutación de nuestra tesis, sino al contrario, es un argumento de la congruencia de su postulado (ver nota 20).

24 "Ax2. El predicado de una proposición negativa es siempre universal, y el de una afirmativa es siempre particular.” (Correia, 2003, p.101). La proposición afirmativa divide siempre el predicado.

25 Esto no significa que la distinción no se 'dé' si es articulada en una proposición negativa. Aún en una proposición negativa ya se ha distinguido algo de algo, aunque ello sea indefinido. Esto es articulado y puede ser demostrado aplicando a la proposición negativa el "Canon de Proclo" o la regla de obversión que establece que: "si en una proposición categórica de tres términos se mantiene su sujeto y su cantidad, pero se cambia su predicado (de definido a indefinido o viceversa), y se cambia también su calidad (de afirmativa a negativa o viceversa), se llega a una proposición que se sigue con la primera recíprocamente.” (Correia, 2003, p.78). En su expresión lógica: Si todo X es no-Y, entonces, ningún X es Y, y, Si algún X es Y, entonces, algún X no es no-Y. 


\section{Silogismo Dialéctico ${ }^{26}:{ }^{27}$}
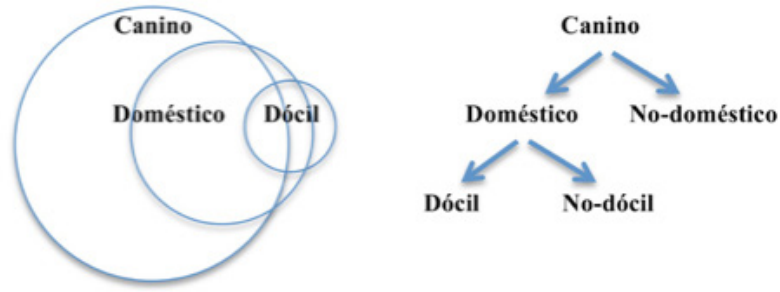

La división aquí es accidental, no por naturaleza. Aristóteles distingue estos dos silogismos para argumentar que no siempre que razonamos correctamente damos con la verdad de las cosas.

Como se ha demostrado, el esquema divisivo nos entrega información adicional a la que provee el esquema inclusivo, a saber, nos muestra tanto la inclusión del sujeto en el predicado como aquello que se excluye de él para poder distinguirlo.

\section{Tipos de división según Boecio}

Aristóteles hizo uso de la división (por ejemplo, Politica 1290b y De generatione et corruptione 330a1). Asimismo, también los primeros peripatéticos la apreciaban, Boecio dice que prueba de ello es el tratado de Andrónico de Rodas (De divisione 875D). Según Boecio hay dos tipos de división, cada una con tres ramas:
1) Secundum se
a. Dividir un género en especies ${ }^{28}$
i. (v.g. animal en racional y no racional)
b. Dividir el todo en sus partes
i. (v.g. las partes de una casa)
c. Dividir un término en sus significaciones propias
i. (v.g. "perro" significa cuadrúpedo capaz de ladrar, una estrella en Orión y un animal marino)

26 La manera demostrativa del silogismo retórico enthymema difiere del silogismo científico en cuanto infiere desde: 1. premisas probables y 2. desde signos, esto es, desde los efectos hacia las causas (A. Po. 2, 27; Ret. 1357a32).

Hamblin nos recuerda que en la Retórica (al final del Libro II) Aristóteles lista los tópicos que forman entimemas falaces. De éstos nos interesan los dos primeros, los cuales se relacionan con las falacias lingüísticas; asimismo, el quinto, sexto y séptimo, que corresponden a las falacias no lingüísticas:

1.- That which arises from the particular words employs (a. Compact wording giving the impression of fresh conclusion. b. Use of similar words for different things); 2.- The assert of the whole what is of the parts, or vice versa; 5.- Representing the accidental as essential; 6.- Argument from consequence; 7.- Representing as causes things which are not causes. La octava y novena parecen ser causas del secundum quid: 8.- Omitting mention of time and circumstances; 9.- Confusion of absolute with particular (Hamblin, 1993, p.71-72).

27 Como se puede ver en este esquema, existe un margen de error dado que lo que se predica del sujeto es un accidente (puede ser así como puede no serlo).

28 Correia nos dice que es valioso notar que en este tipo de divisiones existe una diferencia entre los platónicos y Aristóteles, pues éste último no limita la división a la dicotomía, sino que acepta el número de especies necesarias (con un mínimo de dos) sin que por ello se vaya hasta un número infinito (De divisione $877 \mathrm{C}-\mathrm{D})$ (Cf. Correia, 2011, p.26). 


\section{2) Secundum accidens}

a. Dividir un sujeto en sus accidentes

i. (v.g. el hombre en blanco, negro y color intermedio)

b. Dividir los accidentes en un sujeto

i. (v.g. entre las cosas que se buscan unas pertenecen al alma, otras al cuerpo)

c. Dividir los accidentes en accidentes

i. (v.g. entre las cosas blancas unas son líquidas, otras sólidas) ${ }^{29}$

Presentamos los tipos de división para que se tome en cuenta que la consideración falaz puede darse en cualquiera de ellos. De hecho, resalta a la vista que las consideraciones que da Aristóteles acerca de la falacia del $S Q$ se expresan por las divisiones 1a, 1b, 2a y 2c; mientras la falacia del $A c$ es posible en 1a, 1b, 2a, 2b y 2c. Otras falacias pueden considerarse del mismo modo, por ejemplo, la falacia de la homonimia se muestra claramente en la división secundum se de un término en sus significaciones propias, pues es la variedad de las significaciones en un mismo término lo que produce dicha falacia ${ }^{30}$.

\section{Mostración del esquema divisivo en el tratamiento de las falacias}

\subsection{Falacia del accidente}

Conforme Aristóteles desarrolla los diferentes temas que se encuentran en $S E$, nos señala las siguientes precisiones acerca de la falacia del $A c$ :

1.- La falacia del $A c$ se da "cuando se estima que una cosa cualquiera se da de manera semejante en el objeto y en su accidente." $(S E, 5,166 b 28-30)^{31}$.

2.- La falacia del $A c$ sólo es posible tomándose sobre "una cosa" ( $S E, 6,168 \mathrm{~b} 29)$.

3.- La falacia se origina cuando se predica algún atributo no-esencial, ya sea al objeto o a su accidente. Pero, Aristóteles esclarece que en el caso en donde el objeto sea indistinguible y uno en esencia, todos los atributos tienden a pertenecer a la totalidad $(S E, 24,179 \mathrm{a} 38 \mathrm{f})$ y no se genera falacia ${ }^{32}$. En Categorías Aristóteles

Cf. Correia, 2011, p.26.

30 Según Aristóteles, "los nombres y la cantidad de enunciados son limitados, mientras que los objetos son numéricamente infinitos." (SE, 1, 165a10). Valiéndose de ello los sofistas insertan su engaño.

Este punto no se trabajará en el presente estudio por motivos de espacio. Sin embargo, queda aquí referido para un estudio posterior.

31 En esta falacia podemos identificar tres elementos: El sujeto, su accidente y un predicado (atributo) que se hace hacia uno (Cf. Bueno, 1988, p.10; Schreiber, 2003, p.114-ss.).

32 A. Bueno, basándose en Poste (1931, p.158), indica que el análisis de Aristóteles no esclarece cuándo está permitido inferir de esta forma y cuando no, pues es claro que se puede inferir de esta forma sin incorrección. V.g. Esta herramienta es de madera, y es un martillo. Luego, es un martillo de madera (Cf. Bueno, 1988, p.12). Aristóteles dice que la falacia no se produce cuando el género de las cosas no es distinto, dando el ejemplo: "hombre se predica de hombre individual, y animal se predica de hombre; así, que también del hombre individual se predicará animal: en efecto, el hombre individual es hombre tanto como animal." (Cat. 3, 1b1117). Lo que acusa Poste es que Aristóteles nunca nos dice cuándo no se produce la falacia si lo que se sigue del sujeto es accidental y no necesario o esencial. Sin embargo, Schreiber dice que, si bien Aristóteles no ofrece una regla formal para evitar este malentendido, esta crítica no percibe que Aristóteles ofrece una respuesta a través de una prueba ontológica (SE, 24, 179a37-38). Esta prueba que da Aristóteles tiene relación con la esencialidad del predicado. Ahora, Schreiber nos recuerda que Aristóteles distingue entre dos formas de usar el término

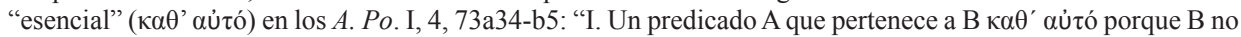


esclarece este punto diciendo:

Cuando una cosa se predica de otra como de un sujeto, todo aquello que se dice del predicado se dice también del sujeto (Cat. 3, 1b10-11).

Pero líneas abajo distingue que si esto se aplica a "cosas de distinto género y no subordinadas entre sí, sus diferencias son también distintas en especie..." A. Bueno lo explica así: "la transitividad de lo predicado está restringido a lo predicado en categoría de sustancia.” (Bueno, 1988, p.16. Trad. propia).

Este pasaje, sin embargo, nos entrega también otra información. Cuando Aristóteles dice "y no subordinadas entre sí", está señalando explícitamente que el modelo divisivo da pauta de la consideración de la cosa, y que este modelo debe ser tomado en cuenta al momento de predicarse algo de ella, en efecto, si no se hace esto puede caerse en error. Bajo este mismo respecto, el filósofo en el SE, 24, 179a2733 dice que si lo que se da sobre el objeto es de necesidad, puede admitirse en el accidente.

4.- Cuando se habla de "accidente" debemos entender cualquier predicado que no sea idéntico al sujeto $(S E, 24,179 \mathrm{a} 38)^{33}$.

5.- 'En el caso de las 'refutaciones aparentes' en función del accidente, 'el error se produce' por no poder discernir lo idéntico y lo distinto, lo uno y lo múltiple, ni a cuáles predicados les sobrevienen todas las mismas cosas que al objeto." (SE, 6, 169b2-5).

Tomando en cuenta todas las consideraciones que provee el peripatético, podemos representar la falacia del $A c$ bajo el siguiente modelo divisivo ${ }^{34}$ :

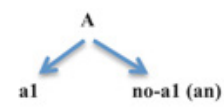

Si A es "una cosa" y sólo una, que tiene uno [a1], dos, o más accidentes [an], al predicar X de A, no por ello puede predicársele X a al o a cualquier otro accidente de

puede ser definido sin A (v.g. la manera en que línea pertenece a triángulo) y, II. Un predicado A que pertenece a B $\kappa \alpha \theta^{\prime} \alpha u ́ \tau o ́$ porque A no puede ser definida sin B (v.g. la manera en que impar pertenece a número)." Dicho esto, Schreiber procede a afirmar que el error del accidente, en el ejemplo del triángulo (SE, 6, 168a40-b3), se produce porque al considerar que el triángulo no se puede definir sin contarse como figura (el caso I) se piensa también que figura no se puede definir sin contarse como triángulo (caso II), lo cual es un error (Cf. Schreiber, 2003, p.116). Esta apreciación de Schreiber da solidez a nuestra interpretación de la falacia del $A c$ como una consideración falaz ante-predicativa que se expresa al modo de la división, pues al mentar definiciones, el modelo de la división nos previene precisamente a diferenciar los géneros de las especies.

33 Véase Bueno, 1988, p.10.

34 Cuando Schreiber se dispone a analizar la falacia del $A c$ bajo un modelo silogístico al modo explicado en los Analíticos Primeros, reconoce que Aristóteles no muestra en las $S E$ intención de explicar la falacia bajo estos términos, sino por el contrario, explica el error enteramente en referencia al tipo de predicación ontológica que se halla en una de las premisas (cf. Schreiber, 2003, p.114-ss.). Parece totalmente justificado, por lo dicho, que no se realice el análisis de las falacias desde su modo argumentativo (si bien es claro que en este modo también se producen), sino que se inicie el estudio de las falacias desde la consideración falaz al nivel ontológico usando el modelo divisivo. Aristóteles hace evidente que la falacia del $A c$ no se genera por una invalidez del silogismo (aunque se expresa de ese modo), sino que su generación está en el descuido de los predicados esenciales y accidentales. 


\title{
A. La misma falacia se produce cuando se predica $X$ esta vez al accidente [a1] y se
} cree que por ello debe darse por necesidad en la cosa [A]. Expresado de otra manera:

\author{
1. Si A es X, no necesariamente a1 será X. \\ 2. Si a1 es $X$, no necesariamente A será $X^{35}$.
}

\section{Para ejemplificar el primer modelo considérese el ejemplo que toma Aristóteles del Eutidemo de Platón (298c) y ofrece en (SE, 24, 179b15):}

35 La falacia del consecuente opera, según Aristóteles, del mismo modo ( $S E, 7,169 \mathrm{~b} 5)$, "pues el consecuente es una parte del accidente". Sin embargo, esto no parece certero, pues la falacia del consecuente se da cuando la consecuencia del sujeto es sustancial, esto es, cuando siempre que se da éste se da aquella. Aristóteles dice que la falacia del consecuente se produce "por creer que la consecuencia es reversible; en efecto, cuando, al existir esto, necesariamente existe aquello, también -creen algunos-, al existir lo segundo, existirá necesariamente lo primero." (SE, 5, 167b1-4). De lo dicho se puede concluir que la falacia del consecuente opera según este modelo $\mathrm{P}=>\mathrm{Q}$ : Si se da $\mathrm{P}$ necesariamente se da Q, pero si se da Q, P no se sigue necesariamente. Este modelo ilustra que Q es esencial a P y jamás accidental. El ejemplo que da Aristóteles lo prueba: "al llover, la tierra queda mojada, si está mojada se supone que ha llovido: pero ello no es necesariamente así.” (SE, 5, 167b78). El "mojar" es esencial a la lluvia, pero la lluvia no es esencial (necesaria) para que algo esté mojado. La consideración falaz opera en creer que si una causa presenta siempre una consecuencia (por necesidad), siempre que se dé esa consecuencia, ésta debe ser atribuía a esa causa, y sólo a ella, descuidando que pueden haber varias que tengan el mismo resultado. Pero Aristóteles ataca la interpretación que acabamos de dar cuando dice que "el consecuente es algo que sobreviene accidentalmente.” (SE, 6, 168b28). ¿Qué quiere decir aquí Aristóteles? Este pasaje puede interpretarse de dos maneras. Primero, que cuando hablamos de la falacia del consecuente no estamos admitiendo que existe necesidad en la consecuencia de una causa. Segundo, que lo consecuente puede ser ciertas veces necesario y ciertas veces accidental, y lo más sensato es ver la consecuencia como un accidente hasta probar su necesidad. La primera interpretación se desintegra al confrontarla con la definición que dio Aristóteles en $S E, 5,167 \mathrm{~b} 1-4$; en cuanto a la segunda interpretación, parece confirmarse en el mismo pasaje de 167 b cuando el filósofo dice "-creen algunos-". Si la interpretación correcta es la segunda, entonces nuestra interpretación también se sostiene.

Por otro lado, Bueno provee la tradicional diferenciación entre estas dos falacias, a saber, que la falacia del $A c$ envuelve tres términos (S es P; S es Q; Luego, P es Q) mientras que la del consecuente solamente dos (Todo S es $\mathrm{P}$; Por tanto, Todo $\mathrm{P}$ es S) siendo la falacia del consecuente un error de convertibilidad de una premisa universal afirmativa (Bueno, 1988, p.11).

También cabe recalcar que Aristóteles distingue entre ambas falacias: mientras la falacia del $A c$ debe ser tomada respecto de una cosa, la del consecuente es respecto de varias $(S E, 6,168 \mathrm{~b} 28-32)$. Schreiber nos hace caer en cuenta de la interpretación general de este pasaje: "By this interpretation, fallacies due to Accident involve mistaking a particular accidental predication for a particular essential predication; fallacies due to Consequent involve mistaking a universal accidental predication for a universal essential predication." (Schreiber, 2003, p.136-137). Sin embargo, Schreiber argumenta que esta interpretación tiene falencias, precisamente porque Aristóteles plantea el ejemplo del triángulo como ilustrativo de la falacia del $A c$ y éste parte de una premisa universal (todos los triángulos son figuras). Schreiber termina concluyendo que en el texto no existe una distinción propiamente establecida entre la falacia del $A c$ y la del consecuente, pues Aristóteles las diferencia pero al mismo tiempo confunde ejemplos que dio de la falacia del consecuente $(S E, 5)$ diciendo que son ejemplos que indican la distinción entre ambas falacias, sólo que ahora los cita como ejemplos de la falacia del $A c(S E, 6)$. Así Schreiber concluye que 1. Aristóteles no tenía una clara distinción entre las dos falacias o 2. tenía una distinción en mente, pero no pudo expresarla propiamente. Podría ser, dice Schreiber, que la solución sea modificar la diferenciación que Aristóteles da en $S E, 6,168 \mathrm{~b} 28$-32 de la siguiente manera: "[difieren una de

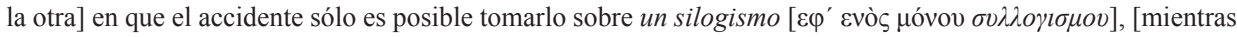

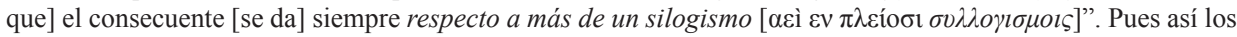
ejemplos coincidirían con esta delimitación. (Véase el análisis completo que hace Schreiber de la falacia del consecuente como conversión de una proposición y como conversión de la conclusión con la premisa mayor en Schreiber, 2003, pp. 133-138). Al final Schreiber argumenta que el intento de Aristóteles por distinguir ambas falacias (SE, 6, 168b27; 7, 169b6-7; 8, 170a4-5) falla y por tanto ambas falacias refieren a un mismo error del razonar (Ibíd, p.139). El modelo divisivo muestra que no es así, pues la falacia del $A c$ se produce al transferir un atributo de la cosa a su accidente (o viceversa), mientras la del consecuente se produce al considerar falsamente que el predicado sobrepasa al sujeto. 
¿Es tu padre el perro?

Si éste [el perro] es un padre y es tuyo, entonces el perro es tu padre.

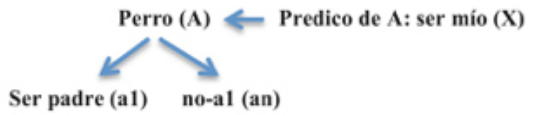

A es X, pero no por ello al es X. Si el perro es mío (A es X), y es un padre (a1), no debe entenderse que es padre respecto de mi (que sea mi padre) a1 es X.

En cuanto al segundo modelo, Aristóteles en Categorías 5, 2a29-34 ${ }^{36}$ nos ofrece un ejemplo que puede entrar dentro de esta consideración de la falacia del Ac. El ejemplo puede resumirse de la siguiente forma:

Este cuerpo es blanco;

Blanco es un color; luego, este cuerpo es un color. ${ }^{37}$

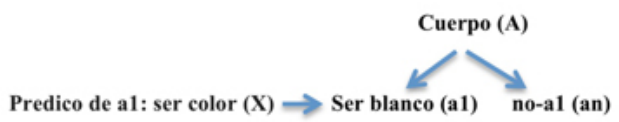

Se predica "ser un color" (X) a blanco (a1). Ahora, por predicar algo verdadero sobre el accidente (que el blanco es un color) se considera erróneamente que también debe ser verdadero que se predique ello de la cosa (del cuerpo). Por lo tanto, la conclusión mienta que el cuerpo (A) es un color (X), lo cual es un error.

Nótese que las relaciones entre los términos y sus predicados son diferentes. Mientras la relación entre Cuerpo y el predicado Blanco es accidental; la relación entre Blanco y lo que se predica de él, a saber, que es un color, es esencial (de manera absoluta). Por tanto, la relación que hay entre los términos de la primera predicación no es la misma que en la segunda ${ }^{38}$.

En conclusión, podemos identificar que la falacia del $A c$ se da por una consideración falaz de la cosa misma que aparenta la posibilidad de una correcta transición de lo predicado sobre el objeto hacia su accidente (o viceversa). Es claro que al formarse el argumento la conclusión resulta falaz, pues se ha irrespetado lo distinguido en la cosa. En todas las revisiones que Aristóteles hace de la falacia, quedan implícitos los tres niveles que hemos señalado: el ante-predicativo (expresado al modo de la división), el predicativo y el argumentativo ${ }^{39}$. Si bien la falacia parece originarse en la forma

36 Los comentaristas de las falacias de Aristóteles, al presentar problemas interpretando la falacia del $A c$, dieron con dos pasajes de Categorías que trataban sobre la relación entre substancia-accidente. Los pasajes son: Cat. 3, 1b10-11 y 5, 2a29-34 (ambos ya los hemos presentado). Pero los comentaristas arguyen que el ejemplo dado en esta última referencia no puede considerarse una falacia del $A c$, pues en él el término medio es en la premisa mayor el sujeto y en la premisa menor el predicado. A diferencia de los ejemplos que ofrece Aristóteles en las $S E$, donde el término medio corresponde en ambas premisas al sujeto (cf. Lloyd, A. "Neoplatonists' Account of Predication and Mediaeval Logic" Colloques Internationaux du Centre National de la Recherche Scientifique. Le Neoplatonisme, Royaumont, 9-13 juin 1969 (Paris:1971), pp. 356-357). Ahora bien, como hemos demostrado, el ejemplo que da Aristóteles en Categorías puede bien acoplarse al modelo de la falacia del $A c$, sólo que en este caso el error se provoca la transición de aquello que se predica verazmente sobre el accidente hacia el objeto.

37 Este tipo de división corresponde a la primera acepción de la división secundum accidens.

38 Esta consideración fue un aporte del Prof. Manuel Correia.

39 Sobre el tratamiento desde un punto de vista silogístico de la falacia del $A c$, su confusión con una falacia lingüística y la argumentación de por qué Aristóteles la considera una falacia extra-lingüística remito a Schreiber, 
lingüística (predicación) su origen verdadero, según Aristóteles, es ontológico ${ }^{40}$.

\subsubsection{Solución de la falacia del accidente a través del modelo divisivo}

Si el error se forma por una consideración errónea de las cosas (de su división) entonces es preciso probar que la solución de las falacias es el resultado de la rectificación de aquella consideración. Schreiber dice que ha persistido un error en confundir la falacia del $A c$ con una falacia lingüística, y mientras que no se admita que su base es ontológica, a saber, en la confusión entre predicados esenciales y accidentales, su resolución será imposible (Schreiber, 2003, p.127). Por ello mismo, el modelo de la división, como hemos demostrado, previene precisamente esta confusión y nos remite a la consideración ante-predicativa (extra-lingüística) de la cual podemos extraer su resolución precisa.

Aristóteles primero reconoce que hay atributos esenciales que se dan necesariamente tanto en el accidente como en la cosa (cuando no se diferencian en cuanto a la entidad y son una misma cosa), pero que, como uno no puede tener certeza absoluta respecto de cuáles atributos se dan con necesidad en ambos y cuáles no, lo más sensato es negar la posibilidad de que el atributo sea transitivo, pero al mismo tiempo hay que reconocer su posibilidad (SE, 24, 179a27-33). Líneas abajo Aristóteles hace una distinción cardinal en lo concerniente a nuestro estudio, dice que la solución de la falacia del $A c$ no se sitúa en la distinción entre lo 'sin más' y lo 'bajo un aspecto', pues aunque el ejemplo del hombre con el velo (179b3-5) puede entrar bajo esta distinción a primera vista, otros ejemplos escapan a esta consideración, así, v.g. si éste es un padre y es tuyo, es tu padre, pues ser padre no admite calificación ${ }^{41}$. Con ello no sólo establece claramente que existe una diferencia entre esta falacia y la del $S Q$, sino que el error tampoco tiene origen lingüístico (interpretando que se ha tomado el término ser homónimamente) ${ }^{42}$. Pues Aristóteles dice que aunque el mismo argumento puede tener varios vicios, no por ello mostrar uno de ellos es resolverlo, sino que hay que identificar su núcleo (179b17-20). Esto es precisamente lo que nos provee el modelo divisivo, pues como hemos identificado, el origen de la falacia es ontológico y por ello su resolución debe apelar a la cosa misma. Schreiber llega a la misma conclusión: el origen de la falacia radica en la no distinción entre

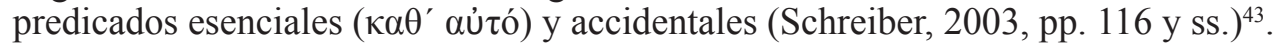

El error está en la consideración falaz de la cosa, la cual lleva a una definición errada, a saber, si bien el accidente no puede darse sin el atributo, no por ello la cosa se comporta del mismo modo para con ese atributo (o viceversa). V.g. Una estatua

2003, Ch.7; y para la razón histórica de su tratamiento como mero error lógico (desde William de Ockham), remito específicamente a las pp.128-130.

40 Cf. Schreiber, 2003, p.120.

41 Según el principio de parsimonia en Aristóteles el tipo de falacia descrito debe concordar con la solución propuesta para dicha falacia. Así, cada ejemplo del mismo tipo de la falacia debe admitir la misma resolución. Esto supone que el error en cada ejemplo es originado por la misma falsa presuposición (cf. Schreiber, 2003, pp. 84-87). Por lo tanto, si ambos ejemplos, tanto el del perro como el del hombre bajo el velo se resuelven como falacias del $A c$ y sólo una de ellas admite la resolución como ejemplo de $S Q$ (o podríamos concebir más radicalmente que se origina en una homonimia), entonces hay que deducir que esta solución es aparente, pues no ataca el origen del error.

42 Se homologarían las dos acepciones del termino ser (estar) en el ejemplo del hombre del velo. No conoces a quien está cubierto; quien está cubierto es Córisco; Luego, no conoces a Córisco. Sobre las falsas interpretaciones de solución de la falacia del $A c$ remito a Schreiber, 2003, pp. 117-128.

43 Ver nota 32. 
no se puede definir sino por ser una obra hecha por alguien. Si ella me pertenece (en cuanto propiedad), no por ello yo soy su creador.

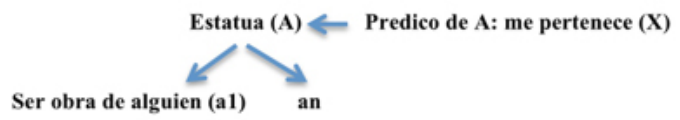

A es X, pero no por ello a1 es X. Aunque es esencial de toda estatua ser obra de alguien, no se puede concebir falazmente que $\mathrm{A} \Leftrightarrow \mathrm{a} 1$, y que por lo tanto lo que se predique de A se dará en a1 con necesidad. La solución, como se ha repetido, es mostrar que se ha considerado falazmente la cosa y que se ha dividido incorrectamente. $\mathrm{Al}$ rectificar la consideración de la división se evita transmitir el error a las premisas del argumento y evitamos la falacia.

\subsection{Falacia de Secundum quid}

La consideración falaz, en el caso del $S Q$, no se suscita en el predicar un atributo al objeto y considerar que éste debe aplicarse necesariamente a sus accidentes (o viceversa), sino que la falsa consideración se produce en un paso anterior: al olvidar las restricciones por las cuales el atributo es predicable del objeto. Aristóteles dice que la falacia del $S Q$ se obtiene "cuando lo que se enuncia como particular se toma como dicho de manera absoluta, [...]" $(S E, 5,167 \mathrm{a} 1)$; y también lo enuncia de la siguiente manera: "En las 'refutaciones' en función de un aspecto y de sin más, el error estriba en la pequeña separación 'entre lo uno y lo otro': pues damos nuestro acuerdo a lo universal como si no añadiera ningún significado ni el algo [la cuantificación particular], ni el en un aspecto, ni el cómo, ni el ahora." $(S E, 7,169 \mathrm{~b} 10)^{44}$. Lo que se puede representar de la siguiente forma:

Si A es X (Restrictivamente)

No por ello, A es X (sin restricción)

Aristóteles nos presenta tres restricciones que debemos tomar en cuenta para no caer en esta falacia:

1ra restricción:

a) Ser algo $\neq$ ser ( $\sin$ más).

b) No ser algo $\neq$ no ser (sin más).

Ejemplos:

Lo que no es, es opinable. Ergo, es $(S E, 5,167 \mathrm{a} 2)$.

Si algo no es hombre (ej: un perro). Ergo, no es (167a3-4).

44 Esta última definición que da Aristóteles ha llevado a que se confunda la falacia del $S Q$ con la del $A c$. Véase como ejemplo el Cambridge Dictionary: "The fallacy of secundum quid (neglecting qualifications) occurs where someone is arguing from a general rule to a particular case, or vice versa. One version of it is arguing from a general rule while overlooking or suppressing legitimate exceptions. This kind of error has also often been called the fallacy of accident. [...] The other version of secundum quid, sometimes also called the fallacy of converse accident, or the fallacy of hasty generalization, is the error of trying to argue from a particular case to a general rule that does not properly fit that case." (Informal fallacy. (1999). In Robert Audi (Ed.), The Cambridge dictionary of philosophy). 
Modelo divisivo:

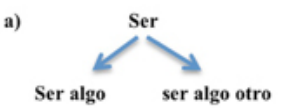

b)

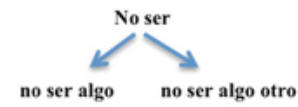

\section{2da restricción:}

a) Ser bajo un aspecto $\neq$ ser simplemente.

b) No ser bajo un aspecto $\neq$ no ser simplemente.

Modelo divisivo:

a)

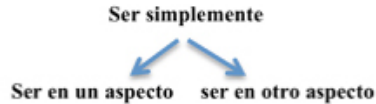

\section{3ra restricción:}

Ser una parte $\neq$ ser el Todo.

No ser una parte $\neq$ no ser el Todo.

Ejemplo:

El ejemplo del etíope (167a10-13) representa a las restricciones 2 y 3.

Una cosa es mitad blanca, mitad negra. Ergo es blanca (o, Ergo es negra) (SE, 5, 167a19).

Modelo divisivo:

a)

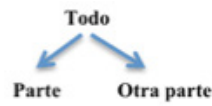

Podemos resumir las tres restricciones en una sola:

Cuando se confunde lo particular (SQ), con lo absoluto (simpliciter).

A es X (particularmente); luego, A es X (simpliciter). Como se puede notar, aquí el error no está en extender el atributo predicado, sino que se produce ignorar la restricción que el objeto muestra.

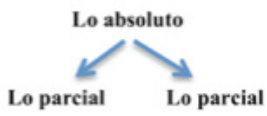

La consideración falaz está en no respetar la división del género en sus especies, del todo en sus partes o del absoluto (sin restricción) en lo parcial (restringido). Tomemos un ejemplo de los que ofrece Aristóteles para confirmar lo dicho:

si habiendo aceptado que el etíope es negro, se preguntara si es blanco de dientes; si, pues, es blanco en este aspecto, se podría creer que la discusión ha establecido que es negro y no-negro, $[\ldots](S E, 5,167 \mathrm{a} 10-13)$.

Se considera una división tipo secundum se del todo en sus partes.

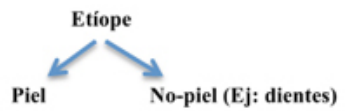


Habiendo cometido desde un principio la falacia del $S Q$ considerando que el etíope es negro (absolutamente), porque su piel (una parte de él) es negra, la cometemos una vez más predicando de sus dientes que son blancos e, infiriendo de lo dicho, que el etíope es blanco absolutamente. Concluyendo que es al mismo tiempo blanco y no-blanco (negro). Este ejemplo que da Aristóteles es curioso porque se produce por un uso doble de la falacia en cuyas conclusiones se produce contradicción ${ }^{45}$.

Como se puede ver, la falacia aquí no se ocasiona en el momento en el que el predicado de la parte se extiende hasta el todo, pues en ese caso tendríamos el modelo segundo de la falacia del $A c$. La falacia es anterior a esta predicación, pues se produce en la consideración errónea de que la parte representa el todo. Esto es indiscutible cuando se considera la falacia, sobre todo, en su primera restricción (tanto en $a$ como en $b$ ). El modelo de la división nos permite visualizar precisamente la división que existe del absoluto en lo parcial, y por ende, no incurrir en dicha falacia.

\subsubsection{Solución de la falacia del Secundum quid a través del modelo divisivo}

La primera solución que nos ofrece Aristóteles es el reconocer que el oponente ignora lo que es una refutación, y por tanto se reduce la falacia a la Ignoratio Elenchi:

Las 'refutaciones aparentes' en función de un aspecto, o sin más, lo son en cuanto que la afirmación y la negación no versan sobre la misma cosa (SE, 6, 168b11-12).

Schreiber nos recuerda que los requerimientos que Aristóteles estipula para una refutación real $(S E, 5,167 \mathrm{a} 21-27)$ son los siguientes:

1. Premisas que no incluyen la conclusión; 2. Una conclusión que se sigue con necesidad de las premisas propuestas; y 3 . Una conclusión que niegue uno y el mismo predicado afirmado por quien responde. Ese predicado negado debe ser: (3a) la cosa significada, no sólo su nombre; (3b) la cosa bajo la misma descripción en la predicación afirmada por quien responde; y (3c) la cosa calificada en precisamente la misma manera según fue afirmada por quien responde (Schreiber, 2003, p. 88. Trad. propia).

Schreiber bien identifica a la falacia del $S Q$ con la acepción 3c. Y la solución que propone Aristóteles sería señalar este error develando que: si bien es imposible que dos cosas contrarias se den sin más en la misma cosa, nada impide que cada una de ellas se dé en un aspecto, respecto a algo, o de alguna manera, o bien que ésta se dé sin más y aquella en algún aspecto ( $S E, 25,180 a 26-29)$. Ésta es la resolución de la falacia al modo de la argumentación. Pero este estudio ha demostrado que el origen de la falacia está antes de la predicación, y por lo tanto cabría demostrar que su solución también debe darse en este nivel y que ésta debe tener el mismo modo representativo de la división. Mostremos la solución valiéndonos del siguiente ejemplo:

45 Es forzado precisamente para darle el carácter silogístico, cuando vemos que antes de formar un silogismo la falacia ya opera. 
¿Es posible que uno mismo, a la vez, cumpla un juramento y perjure? [...] en efecto, el que ha jurado que perjurará, al perjurar, cumple su juramento [...] $(S E, 25,180 \mathrm{a} 34-\mathrm{b} 1)$.

Si dividimos al sujeto en sus accidentes, tomando ahora por accidentes sus acciones obtenemos que:

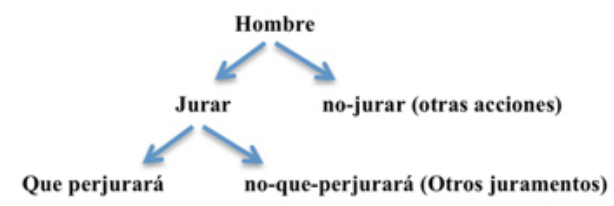

Vemos claramente bajo este modelo que el hombre actúa y dentro de sus actos es capaz de jurar, pero que aquello de lo que jura siempre tiene una acepción (jurar algo). Por tanto, la consideración falaz está en pensar que si el hombre ha jurado que perjurará, este acto equivale a todos los juramentos: descuidando que el predicado ya ha dividido al sujeto (que el género ha sido dividido en sus especies). Se descuida que al distinguir de jurar, que se ha jurado de esto, ya se ha dividido en esto y noesto. Por tanto, se descuida la restricción con la que se ha predicado. La resolución está en considerar correctamente que se ha irrespetado la división igualando al sujeto con el predicado, o en los términos que lo pone Aristóteles:

[...] si uno cumple un juramento sobre esto o en este aspecto, [no por ello] es necesario también que cumpla los juramentos (sin más) (en efecto, el que ha jurado que perjurará, al perjurar, cumple su juramento sólo en esto, pero no cumple los juramentos 'en general') (SE, 25, 180a36-b1).

\section{Diferencia entre las falacias del accidente y del secundum quid}

A partir de las varias interpretaciones que se ha dado de la falacia del $A c^{46}$ se ha llegado a una confusión respecto de ésta, y a partir de la interpretación de Antoine Arnauld y Pierre Nicole en su Port Royal Logic (1662), a saber, que la falacia del $A c$ "consiste en formular una conclusión que es absoluta, simple, y sin ninguna restricción, desde algo que es sólo cierto accidentalmente" ${ }^{47}$, se ha llevado a la confusión entre las falacias del $A c$ y del $S Q^{48}$. Whately, en su Elements of Logic (1826) distinguirá entre las dos falacias pero introducirá un nuevo error: afirmar a las falacias del $A c$ y $S Q$ como falacias conversas "en cada uno de los cuales se utiliza el término medio, en una premisa para significar algo considerado simplemente, en sí mismo, en cuanto a su esencia; y en la otra premisa, a fin de implicar que sus accidentes son abarcados con ello." (Whately, 1826, p. 219). De Morgan toma esta interpretación de Whately y añade: "Las falacias extra dictionem se establecen de la siguiente forma: 1. La fallacia accidentis; 2. aquella dicto secundum quid ad dictum simpliciter. La primera de éstas debería ser llamada a dicto simpliciter ad dictum

46 Véase Bueno, 1988, pp.16-23.

47 La logique au l'art de penser, 5th ed. (Paris, 1683), reprint, intr. L. Marin (Paris, 1970), III. Xix.4. En Bueno, 1988, p. 21-2.

48 Pues recuérdese que Aristóteles define la falacia $S Q$ como aquella que se produce "cuando lo que se enuncia como particular se toma como dicho de manera absoluta." (SE, 5, 167a1-3). 
secundum quid, pues las dos están correlacionadas en la manera en que se describe en las dos frases [latinas]. La primera consiste en inferir del sujeto con un accidente, lo que se dio como premisa tan sólo del sujeto: la segunda, en inferir del sujeto aquello que se concedió como premisa del sujeto con un accidente" (De Morgan, 1926, pp.291-2). John Stuart Mill adoptará esta interpretación de De Morgan ${ }^{49}$. Hamblin también las describe como falacias conversas entre sí, pues mientras la falacia del $A c$ argumenta inapropiadamente de lo general a lo particular, la falacia del $S Q$ lo hace desde lo particular a lo universal (Hamblin, 1993, p.28). El mal entendido no sólo se da por las explicaciones y ejemplos oscuros que da Aristóteles sino también por las diferentes y muy diversas interpretaciones que se han dado a lo largo de los comentaristas de estas falacias.

Nuestro estudio, sin embargo, ha arrojado información que permite diferenciar estas dos falacias y da argumentos para no considerarlas emparentadas. La principal diferencia que encontramos entre dichas falacias, utilizando el método que hemos mostrado, es que en $S Q$ el error se produce por una falsa consideración de lo que se dice de la cosa en cuanto a su restricción, pues se presenta un atributo de manera restrictiva y se concluye de la misma cosa el atributo sin restricción. Por el contrario, la falacia del $A c$ deviene cuando uno predica algo a la cosa $y$ lo transfiere sin consideración a su accidente o viceversa. El error $S Q$ está en la consideración de lo que se predica, no en su transferencia.

Sin embargo, algunos ejemplos que da Aristóteles del $S Q$ se adaptan al segundo modelo de la falacia del $A c$ y podemos creer que por ello se los ha considerado contrarios o emparentados ${ }^{50}$. Tomemos el ejemplo del etíope que se presenta como ejemplo de la falacia del $S Q$. En su afán de mostrarse silogísticamente, este ejemplo desvía la mirada al error originario. Por tratarse de un doble error $S Q$ este ejemplo puede ser representado por el segundo modelo de la falacia del $A c$ :

El etíope es negro de piel, pero es blanco de dientes. Luego, es blanco y no-blanco (SE, 5, 167a7). Y si se ha dicho que es negro (por su piel, originándose aquí la falacia del $S Q$ ) se llega a contradicción al comparar ambas conclusiones $(S E, 5,167$ a10).

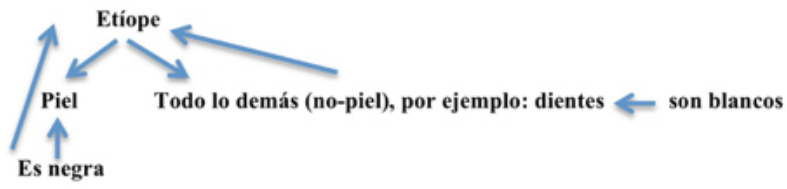

En este gráfico se puede ver, tal como sucede en el segundo modelo de la falacia del $A c$ (si al es X, no necesariamente, A lo será) que si predico algo del accidente (en este caso de la parte), no por ello puedo concluir que se da con necesidad en el sujeto (como un todo).

Otro aspecto que emparenta las dos falacias y puede provocar confusión es el hecho de que cuando se predica algo, pero este algo es restrictivo, la falacia del $A c$ se relaciona con la del $S Q$. Aristóteles mismo da un ejemplo y previene justamente

49 Sobre la historia de la falacia del $A c$ remito a Bueno, A. (1988).

50 También se ha dado lo contrario, a saber, se ha tratado de resolver ejemplos de la falacia del $A c$ considerándolos ejemplos de la falacia del $S Q$. El ejemplo del hombre cubierto por el velo ( $S E, 24,179 \mathrm{a} 34-\mathrm{b} 4)$ es muestra de ello, pues, a diferencia del ejemplo del perro y el padre, mientras "conocer a x" admite calificación, ser "padre de x" no la admite. Sin embargo, Aristóteles arguye que ambos son ejemplos de la misma falacia (del accidente) y por ello deben resolverse de forma semejante. Véase a detalle sobre esta diferenciación en Schreiber, 2003, p.123-126. 
de que no se lo interprete como un argumento de doble sentido: "Saber y no saber la misma cosa", en la medida en que se sabe un aspecto y se ignora otro. Ergo, se sabe y no se sabe sobre la misma cosa (pero en diferentes aspectos) ( $S E, 24,179 \mathrm{~b} 29)$ o bien lo que dice Aristóteles en este otro pasaje (179b38-ss):

[...] el < argumento > de alguno de los males es bueno: pues la prudencia es el conocimiento de los males. Pero que esto sea de estas cosas no se dice de muchas maneras, sino $<$ significa $>$ que es una propiedad suya. ([...], y, si algo se dice respecto de los males como $<$ siendo $>$ de algo, es por ello mismo $<$ propiedad $>$ de los males, pero no uno de los males), es porque lo parece, por $<$ decirse $>$, en un aspecto, o de manera absoluta (SE, 24, 180a5-12).

En suma, si bien algunos ejemplos pueden adaptarse a ambos modelos, no por ello se puede concluir que la falacia del $S Q$ es opuesta a la del $A c$. La confusión está en que la falacia del $S Q$ va de lo restrictivo a lo absoluto (simpliciter) y esto puede aplicarse a un sujeto y sus accidentes. Pero vale tener presente que la falacia del $A c$ necesita de un atributo que sobrevenga al sujeto y que sea falsamente transferido a su accidente (o viceversa).

\section{Conclusión}

De todo lo expuesto puede llegarse a dos conclusiones importantes. Primero, se ha hecho patente que toda consideración (ante-predicativa) lleva una distinción y que ésta se devela en la predicación afirmativa. Y de ello se desprende que toda predicación afirmativa implica una división. Si bien toda predicación es una composición de sujeto y predicado, se ha demostrado que toda predicación afirmativa también implica una división del predicado por parte del sujeto, en la cual el sujeto incluye todo lo que le es propio de aquel predicado y, al mismo tiempo, excluye todo lo que se encuentra en el predicado pero que no le pertenece. Segundo, se ha probado que las falacias del $A c$ y $S Q$ se producen primeramente no por un silogismo defectuoso, sino por una consideración falaz ante-predicativa que transmite el error a la proposición. Queda así abierto el estudio de las falacias bajo este parámetro, estudio que deberá ser abordado de manera que nos permita inferir satisfactoriamente la validez del método de la división en la consideración de todas las falacias sofísticas. Si se prueba aquello, a saber, que el modelo divisivo desarrollado por Platón se encuentra presente en el tratamiento de las falacias, será un argumento a favor a la tesis de 1929 de Friedrich Solmsen, quien en ella sostuvo que en las $S E$ se encontraba un modelo lógico más informal que formal y que por lo mismo este escrito debía ser puesto al comienzo de los escritos lógicos de Aristóteles ${ }^{51}$.

La división nos dice el "qué es" la cosa (su definición), pero no la demuestra. No provee su causa (el porqué) (A. Po. Cap. 5-8). Sabio es aquel quien sabe el 'porqué' de las cosas, experto es aquel quien sabe tan sólo el 'qué' de las mismas ${ }^{52}$. Pero

51 Esta posición es compartida por varios especialistas. Hamblin, por ejemplo, ubica este escrito en los últimos años que Aristóteles permaneció en la Academia de Platón o pocos años después de salir de ella (Hamblin, 1993, p. 52-53). El orden que tenían los tratados desde la antigüedad no pertenecía al orden en el que fueron escritos, sino al orden pedagógico en el que eran enseñados. Véase: Solmsen, F. "Boethius and the History of the Organon." The American Journal of Philology. Vol.65, No.1 (1944), pp.69-74.

52 Cf. Met. I, 981a28-39. 
el sofista no busca saber lo uno ni lo otro. No intenta argumentar, sino aparentar, por eso propone divisiones de términos accidentales por las cuales nos lleva a concebir falazmente el 'qué es', pues para concebirlo correctamente es necesario que los términos sean universales (esenciales) ${ }^{53}$ y que de éstos se desprenda la demostración ${ }^{54}$. Las divisiones de las cuales hace uso la sofística versan sobre los términos accidentales; luego, el sofista divide, pero no divide en pro de la definición, sino en búsqueda de la apariencia. Y bien podemos nosotros dirigirnos a las cosas y considerarlas correctamente, así no permitiremos que el sofista nos engañe como lo hace un mago con su audiencia ${ }^{55}$.

\section{Referencias bibliográficas}

Aristóteles. Tratados de lógica. Organon I. Madrid: Gredos, 1994.

Aristóteles. Tratados de lógica. Organon II. Madrid: Gredos, 1995.

Aristóteles. Sophistical Refutations. London: Harvard University Press, 1995.

Aristotle. Aristotle on Fallacies or The Sophistici Elenchi. Trans. And ed. Poste, E. (London, 1866), 1931.

Bueno, A. Aristotle, the Fallacy of Accident, and the Nature of Predication: A Historical Inquiry. Journal of the History of Philosophy, Volume 26, Number 1, pp.5-24, 1988.

Buridan, J. Compendium Totius Logicae (Venice, 1499), facsímile ed., tractatus VII, unpaginated. Frankfurt/Main: Minerva, 1965.

Correia, M. Boecio. Los Tratados silogísticos. Santiago de Chile: Ediciones Universidad Católica de Chile, 2011.

Correia, M. La lógica de Aristóteles. Santiago de Chile: Ediciones Universidad Católica de Chile, 2003.

De Morgan, A. Formal Logic. (London, 1847, reprint. Ed. A.E. Taylor, London, 1926).

Hamblin, C.L. Fallacies. Virginia: Vale Press, 1993.

Kneale, W; Kneale, M. El desarrollo de la lógica. Madrid: Tecnos, 1980.

Lloyd, A. "Neoplatonists' Account of Predication and Mediaeval Logic" Colloques Internationaux du Centre National de la Recherche Scientifique. Le Neoplatonisme, Royaumont, 9-13 Juin 1969 (Paris:1971), 356-357.

Schreiber, S. Aristotle on false reasoning: language and the world in the Sophistical Refutations. Albany: State University of New York Press, 2003.

Solmsen, F. Die Entwicklung der aristotelischen Logik und Rhetorik. (Neue philologische Untersuchungen herausg. von Werner Jaeger, Heft. 4). Berlin. Weidmann, 1929.

Solmsen, F. "Boethius and the History of the Organon". The American Journal of Philology. Vol.65, No.1, 1944.

Whately, R. Elements of Logic. (London), American ed. New York: Herper and Brothers. n.d, III, 1826.

Informal fallacy. In Robert Audi (Ed.), The Cambridge dictionary of philosophy, 1999. Retrieved from: http://search.credoreference.com.ezproxy.puc.cl/content/entry/cupdphil/ informal_fallacy

53 “[...] los predicados contenidos en el qué es son universales (y las cosas universales son necesarias)" (A. Po. II, $13,96 \mathrm{b3}-4)$.

54 “[...] ni es posible conocer sin demostración el qué es de aquello de lo que es causa otra cosa, ni hay demostración de ello, [...]." (A. Po. II, 8, 93b17-20).

55 Agradezco las sugerencias y consideraciones del Prof. Manuel Correia. 